\title{
Aplikasi Persamaan Fungsi Kuadrat Dalam Mencari Karakteristik Hubungan Antara Kecepatan Putaran Motor dengan Laju Aliran Air
}

\author{
Bobby Demeianto ${ }^{1}$ \\ Program Studi Permesinan Kapal, Politeknik Kelautan dan Perikanan Dumai, Dumai 28826 \\ Email: boby.demeianto@gmail.com \\ Boby Wisely Ziliwu ${ }^{1}$ \\ Program Studi Permesinan Kapal, Politeknik Kelautan dan Perikanan Dumai, Dumai 28826 \\ Email : bobywisel@gmail.com
}

\begin{abstract}
Water Treatment Plant called IPA 1 located on Jl. Penjernihan II No.1 Pejompongan is one of the water installations owned by a water treatment company in DKI Jakarta that operates 24 hours non-stop to produce clean water with a capacity of 2500 liters per second (2500 lps). In a Water Treatment Installation (IPA) there is a process of processing and distributing water, to distribute water needs needed auxiliary equipment that is able to supply clean water as needed. In water supply applications at water treatment plants (IPA), the need for clean water, especially in the capital city of DKI Jakarta, is increasingly increasing, making the pump's performance even greater in its distribution so that it often ignores the amount of energy used in producing and distributing clean water. Testing a distribution pump is needed to determine the working characteristics of a pump. One of the variables tested to determine the pump's working characteristics in terms of electricity is to test the relationship between the motor rotation speed used (RPM) and the flow rate of water generated from the pump (liters / second). It can be seen that if the electric motor used to rotate the pump works in a low rotation, then the electric power used will be low and vice versa. One obstacle that may be faced when we are going to do a test to find out the motor rotation characteristics with the flow rate of water, especially in a water treatment plant in Jakarta is that the distribution of water to the public should not be interrupted when we do the testing, so the data obtained will be difficult to obtain completely, especially when the motor rotates at low speed. One approach that can be taken to look for values that are not measurable is to use polynomial regression. The purpose of this study is to look for variables that cannot be measured at the time of the test, especially the water speed rate variable at each motor rotation change which is regulated by Variable Speed Drive (VSD) on motor pumps number two, three, and four using formula obtained from the coefficients of the polynomial regression method. One formula produced by this polynomial regression is $Q=0.0005 N^{2}-0.2231 N-14.101$, with an $R^{2}$ value of $99.79 \%$, where $Q$ is the water flow rate (liters / second) and $N$ is the motor rotation speed (RPM) ).

Keywords : Polynomial regretion; flow rate; motor rotation speed; Variable Speed Drive (VSD )
\end{abstract}

ABSTRAK: Instalasi Pengolahan Air IPA 1 yang berlokasi di Jl. Penjernihan II No.1 Pejompongan merupakan salah satu instalasi air yang dimiliki sebuah perusahaan pengolahan air di DKI Jakarta yang beroperasi selama 24 jam non stop untuk menghasilkan air bersih dengan kapasitas 2500 liter per detik (2500 lps). Pada suatu Instalasi Pengolahan Air ( IPA ) terdapat proses pengolahan dan pendistribusian air, untuk mendistribusikan kebutuhan air dibutuhkan peralatan bantu yang mampu menyuplai air bersih sesuai dengan yang dibutuhkan. Dalam aplikasi penyuplaian air pada instalasi pengolahan air (IPA), kebutuhan air bersih khususnya di daerah ibu kota DKI Jakarta semakin lama semakin meningkat membuat kinerja pompa semakin besar dalam pendistribusiannya sehingga sering mengabaikan besarnya energi yang di pakai dalam menghasilkan dan mendistribusikan air bersih. Pengujian suatu pompa distribusi diperlukan untuk mengetahui karakteristik kerja dari suatu pompa tersebut. Salah satu variable yang diuji untuk mengetahui karakteristik kerja pompa tersebut dalam hal kelistrikannya adalah dengan menguji karakteristik hubungan kecepatan putaran motor yang digunakan ( RPM ) dengan laju aliran air yang dihasilkan dari pompa tersebut ( liter / detik ). Dapat diketahui bahwa apabila motor listrik yang dipakai untuk memutar pompa bekerja dalam putaran yang rendah, maka daya listrik yang dipakai pun akan rendah begitu pula sebaliknya. Salah satu kendala yang mungkin dihadapi pada saat kita akan melakukan pengujian untuk mengetahui karakteristik putaran motor dengan laju aliran air khususnya pada suatu instalasi pengolahan air di Jakarta adalah distribusi air kepada masyarakat tidak boleh terganggu pada saat kita melakukan pengujian, sehingga data yang diperoleh akan sulit didapatkan secara lengkap khususnya pada saat motor berputar pada putaran rendah. Salah satu pendekatan yang dapat dilakukan untuk mencari nilai-nilai yang tidak terukur tersebut adalah dengan menggunakan regresi polynomial. Tujuan dari penelitian ini adalah mencari variable-variabel yang tidak dapat terukur pada saat dilakukannya pengujian, khususnya variabel laju kecepatan air pada setiap perubahan putaran motor yang diatur oleh Variable Speed Drive ( VSD ) pada motor-pompa nomor dua, tiga, dan empat dengan menggunakan rumus yang didapatkan dari koefisien-koefisien metode regresi polynomial. Salah satu rumus yang dihasilkan dengan regresi polynomial ini adalah $\mathbf{Q}=\mathbf{0 . 0 0 0 5} \mathbf{N}^{2}-\mathbf{0 . 2 2 3 1} \mathbf{N}-\mathbf{1 4 . 1 0 1}$, dengan nilai $\mathbf{R}^{2}$ sebesar $99,79 \%$, dimana variable $Q$ merupakan laju aliran air ( liter / detik ) dan variable $\mathrm{N}$ merupakan kecepatan putaran motor ( RPM ).

Kata kunci : Regresi Polynomial; laju aliran air; kecepatan putaran motor; Variable Speed drive

\section{PENDAHULUAN}

Sebuah perusahaan yang bergerak dalam bidang pengolahan air di DKI Jakarta memiliki beberapa

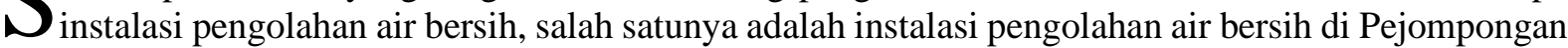
1 yang di sebut dengan IPA-1. IPA-1 sendiri memiliki kapasitas produksi hingga 2500 liter per detik (lps) yang melayani wilayah Jakarta, Senayan dan Kebayoran. Stasiun pompa ini memiliki lima buah

\footnotetext{
${ }^{1}$ Program Studi Permesinan Kapal, Politeknik Kelautan dan Perikanan Dumai, Dumai 28826- Riau
} 
pompa distribusi yang terdiri dari tiga buah pompa besar berkapasitas 1000 lps dengan daya $540 \mathrm{~kW}$ dan dua buah pompa kecil berkapasitas 500 lps dengan daya $280 \mathrm{~kW}$.

Pada instalasi IPA-1 pemasok daya yang digunakan untuk menggerakkan motor-motor pompa tersebut bersumber dari energi listrik PLN yang kemudian diatur penggunaannya dengan cara directon-line. Artinya pompa bekerja selalu menggunakan tenaga maksimumnya, sehingga untuk menghasilkan jumlah aliran serta tekanan tertentu hanya bisa dilakukan penyesuaian terhadap besarnya bukaan katup di sisi keluaran (outlet) pompa.

Dengan mengandalkan pola pengaturan seperti itu maka energi yang dipakai untuk memutar pompa akan terbuang percuma. Ini diakibatkan karena kecepatan motor pompa akan selalu tetap pada posisi kecepatan maksimumnya, walaupun untuk bukaan katupnya sendiri selalu dirubah-rubah / divariasikan. Efek selanjutnya adalah jumlah daya yang dibutuhkan akan meningkat.

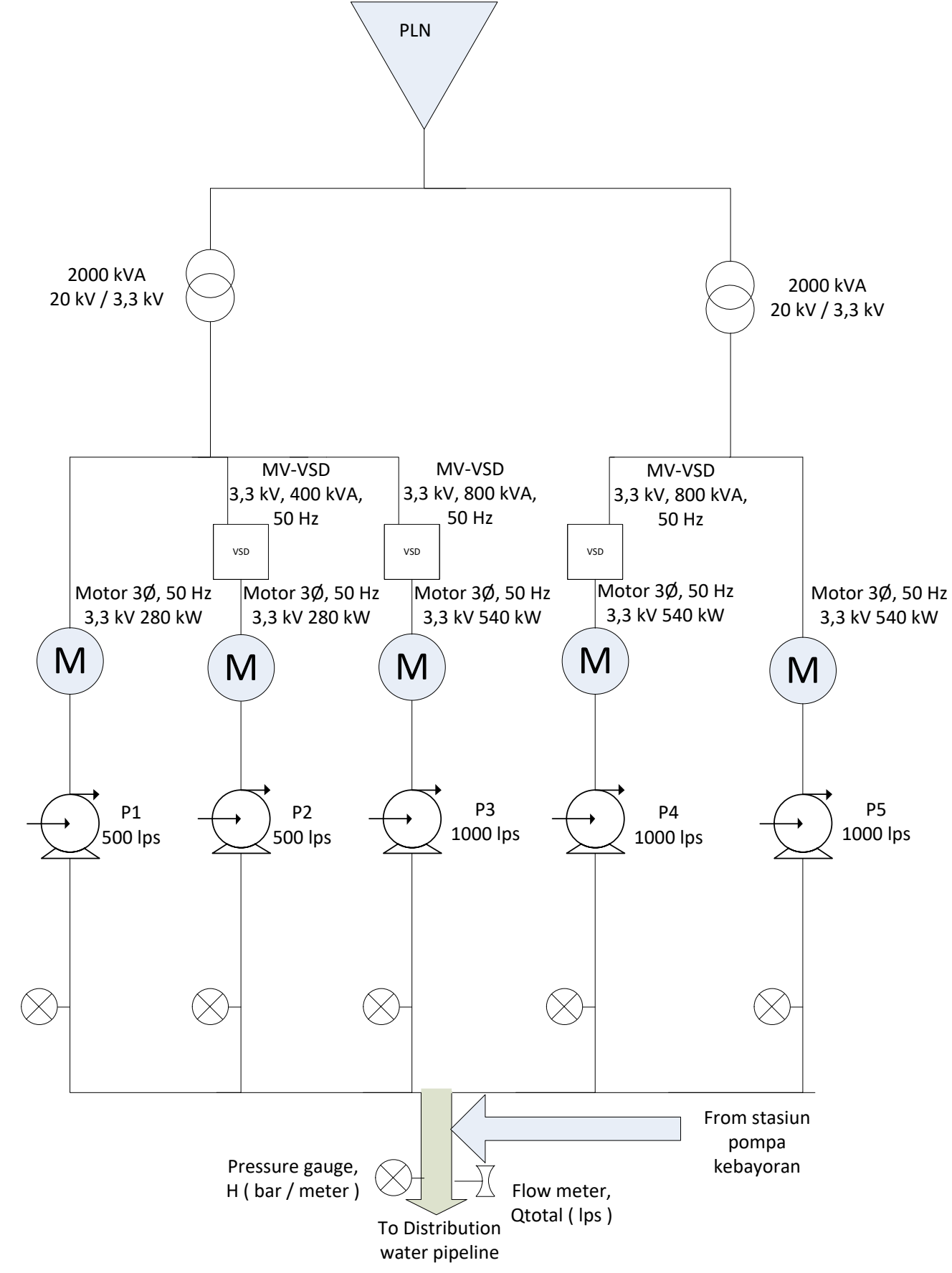

- Gambar 1 Single line Diagram stasiun pompa Jakarta, IPA 1 
Seperti terlihat pada Gambar 1, stasiun pompa Jakarta memiliki lima buah pompa distribusi yang terdiri dari tiga buah pompa besar berkapasitas 1000 lps dengan daya $540 \mathrm{~kW}$ dan dua buah pompa kecil berkapasitas 500 lps dengan daya $280 \mathrm{~kW}$.

Dalam suatu proses pengolahan air bersih diperlukan upaya yang membutuhkan biaya produksi yang tidak sedikit jumlahnya, sehingga diperlukan usaha mereduksi biaya produksi yang berasal dari pembiayaan air baku, bahan kimia, electrical dan manpower.

Sampai dengan saat ini perusahaan pengolahan air tersebut terus melakukan improvement dari berbagai aspek salah satunya adalah aspek energi yang sasaran utamanya adalah untuk menurunkan konsumsi pemakaian energi tanpa mengurangi target produksi. Salah satu cara yang dapat ditempuh dalam rangka mengurangi biaya produksi itu adalah dengan melakukan pemasangan Medium Voltage Variable Speed Drive ( MV-VSD ).

Dari instalasi MV-VSD pada stasiun pompa Jakarta IPA 1 tersebut diharapkan dapat menurunkan pemakaian energi listrik yang secara langsung dapat menurunkan biaya produksi yang berasal dari pemakaian energi listrik.

Tujuan penelitian

Tujuan dari penelitian ini adalah :

1. Mencari karakteristik dan koefisien polynomial pada masing-masing motor-pompa nomor dua, tiga, dan empat dengan menggunakan data kecepatan putaran motor dan kecepatan laju aliran air yang didapatkan pada saat pengujian.

2. Mencari variable-variabel yang tidak dapat terukur pada saat dilakukannya pengujian, khususnya variabel laju kecepatan air pada setiap perubahan frekuensi MV-VSD pada motor-pompa nomor dua, tiga, dan empat dengan menggunakan rumus yang didapatkan dari koefisien-koefisien metode regresi polynomial.

Pengertian pompa

\section{LANDASAN TEORI}

Pompa adalah mesin atau peralatan mekanis yang digunakan untuk menaikkan cairan dari dataran rendah ke dataran tinggi atau untuk mengalirkan cairan dari daerah bertekanan rendah ke daerah yang bertekanan tinggi dan juga sebagai penguat laju aliran pada suatu sistem jaringan perpipaan.

Setiap pompa dirancang pada kapasitas dan head tertentu, meskipun dapat juga dioperasikan pada kapasitas dan head yang lain. Efisiensi pompa akan mencapai maksimum pada designed point tersebut, yang dinamakan dengan titik BEP.Untuk kapasitas yang lebih kecil atau lebih besar efisiensinya akan lebih rendah. Efisiensi pompa adalah perbandingan antara daya hidrolis pompa dengan daya poros pompa.

$$
\eta_{\text {Pump }}=\frac{P_{H}}{P_{S}}
$$

Daya hidrolis adalah daya yang diperlukan oleh pompa untuk mengangkat sejumlah zat cair pada ketinggian tertentu. Daya hidrolis dapat dicari dengan persamaan berikut :

Dimana :

$$
P_{H}=\frac{\rho \times g \times H \times Q}{1000}(\text { kilo Watt })
$$

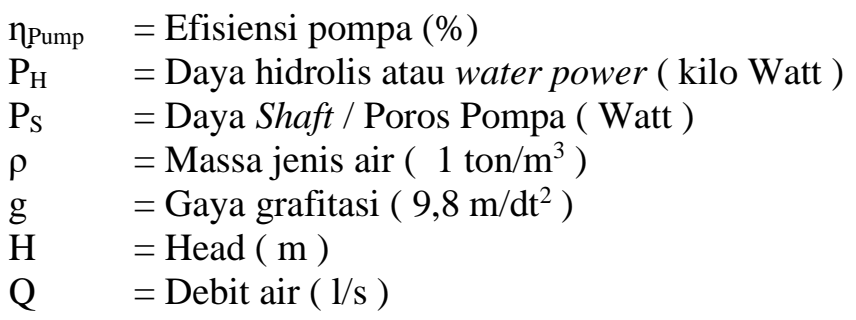

Pompa digerakkan oleh motor. Daya dari motor diberikan pada poros pompa untuk memutar impeler yang dipasangkan pada poros tersebut. Karena pompa digerakkan oleh motor listrik (motor penggerak), jadi daya guna kerja pompa adalah perbandingan antara gaya mekanis yang diberikan motor kepada pompa.

Untuk mencari daya guna kerja pompa ada beberapa tahap menggunakan rumus:

1. Daya yang diberikan motor pada pompa

$P=\sqrt{3} x V \times I x \operatorname{Cos} \theta$ ( Watt)

Dimana : 
$\mathrm{P} \quad$ = Daya yang diberikan motor pada pompa ( Watt )

$\mathrm{V} \quad=$ Tegangan ( Volt )

I $\quad=$ Arus $($ Ampere $)$

$\operatorname{Cos} \Theta=$ Faktor daya motor penggerak

2. Daya rotor (motor penggerak) adalah jumlah energi yang masuk motor penggerak dikalikan efisiensi motor penggerak. Dirumuskan dengan persamaan:

$\mathrm{P}_{\text {rotor }}=\mathrm{P}_{\text {motor }} \times \eta_{\text {motor }}($ Watt $)$

Dimana :

$\mathrm{P}_{\text {motor }}$ = Daya motor ( Watt )

$\eta_{\text {motor }}=$ Efisiensi motor penggerak $(\%)$

3. Pada rumus (1) diketahui bahwa untuk mencari efisiensi kerja pompa adalah daya hidrolis dibagi dengan daya poros pompa, dimana daya poros pompa adalah daya yang dihasilkan dari putaran rotor motor listrik dikalikan dengan efisiensi koplingnya atau dapat ditulis dengan persamaan :

$P_{S}=\frac{\eta_{\text {transmisi }} x P_{\text {rotor }}}{(1+\alpha)}($ Watt $)$

Dimana :

Ps $\quad=$ Shaft power atau daya poros ( Watt $)$

$\eta_{\text {transmisi }}=$ Efisiensi transmisi ( nilai koefisien $=1$ )

$\alpha=$ margin faktor motor penggerak $($ nilai koedisien $=0.1)$

Performansi masing-masing motor-pompa dapat diketahui dengan menggunakan pendekatan regresi polynomial. Penulisan tesis ini akan mengaplikasikan pendekatan regresi polynomial untuk mengetahui perubahan laju aliran air pada masing-masing motor-pompa pada stasiun pompa Jakarta IPA 1 khususnya motor-pompa yang telah dipasang MV-VSD. Seperti telah diketahui bahwa MV-VSD merupakan suatu peralatan yang dibutuhkan untuk mengatur kecepatan putaran motor dengan cara mengatur input frekuensi pada motor tersebut. Pada penulisan tesis ini akan diaplikasikan penggunaan pendekatan regresi polynomial dengan menggunakan variable pengaruh perubahan kecepatan putaran motor (rpm) dengan perubahan laju aliran air pada pompa distribusi stasiun pompa Jakarta IPA 1.

\section{Penggunaan Variable Speed Drive ( VSD )}

Pengendalian kecepatan pompa merupakan cara yang paling efisien dalam mengendalikan aliran, sebab jika kecepatan pompa berkurang maka pemakaian daya juga berkurang. Metoda yang biasanya banyak digunakan untuk menurunkan kecepatan pompa adalah Penggerak Kecepatan yang Bervariasi/ Variable Speed Drive (VSD).

VSD memperbolehkan pengaturan kecepatan pompa berada diatas kisaran yang kontinyu, menghindarkan kebutuhan untuk melompat dari satu kecepatan ke kecepatan lainnya sebagaimana yang terjadi dengan pompa yang berkecepatan berlipat. Kecepatan pompa dengan pengendali VSD menggunakan dua jenis sistim:

- VSD mekanis meliputi sarang hidrolik, kopling fluida, dan belts dan pully yang dapat diatur-atur.

- VSD listrik meliputi sarang arus eddy, pengendali motor dengan rotor yang melingkar, pengendali frekuensi yang bervariasi/ variable frequency drives (VFDs). VFDs adalah yang paling populer dan mengatur frekuensi listrik dari daya yang dipasok ke motor untuk mengubah kecepatan perputaran motor.

Untuk beberapa sistim, VFDs menawarkan sesuatu yang berharga untuk memperbaiki efisiensi operasi pompa pada kondisi operasi yang berbeda-beda. Pengaruh pelambatan kecepatan pompa pada operasi pompa berpengaruh ketika VFD menurunkan RPM pompa, kurva head/aliran dan daya bergerak turun dan ke arah kiri, dan kurva efisiensi juga bergeser ke sebelah kiri. Keuntungan utama penggunaan VSD disamping penghematan energi adalah (US DOE, 2004):

- Memperbaiki pengendalian proses sebab dapat memperbaiki variasi- variasi kecil dalam aliran lebih cepat.

- Memperbaiki kehandalan sistim sebab pemakaian pompa, bantalan dan sil jadi berkurang.

- Penurunan modal dan biaya perawatan sebab kran pengendali, jalur by-pass, dan starter konvensional tidak diperlukan lagi. Kemampuan starter lunak: VSD membolehkan motor memiliki arus start-up yang lebih rendah. 


\section{METODE PENELITIAN}

Pada saat melakukan pengujian dan pengambilan data pada motor pompa setelah dilakukan pemasangan MV-VSD kendala yang dihadapi adalah pertama, tidak adanya alat pengukur laju aliran air atau yang disebut dengan flow meter pada masing-masing outlet pompa. Hal ini mengakibatkan kita tidak dapat mengetahui kinerja pompa tersebut melalui kenaikan laju aliran air setelah kecepatan motor ditambah melalui MV-VSD. Kendala yang kedua adalah, pengujian dan pengukuran yang dilakukan harus menyesuaikan dengan regime pendistribusian air pada saat pengujian. Hal ini agar pendistribusian air kepada pelanggan tidak terganggu.

Dikarenakan pengujian tersebut tidak boleh mengganggu aktifitas pendistribusian air ke pelanggan, maka pengujian dilakukan satu persatu dan disesuaikan dengan kebutuhan pendistribusian air kepada pelanggan. Dengan kata lain bahwa pengujian dilakukan dengan mengupayakan agar $\mathbf{Q}_{\text {total }}$ Sama dengan pump regime pada saat pengujian. Adapun parameter-parameter yang diukur adalah parameter yang nanti akan digunakan sebagai data perhitungan dalam penelitian. Parameter-parameter tersebut adalah :

1. Frekuensi $(\mathrm{Hz})$,

2. Putaran motor (rpm),

3. $\operatorname{arus~listrik}(\mathrm{A})$,

4. Flow/Q (1/s) dan

5. Head $(\mathrm{m})$

Menurut referensi [3] dan [4], salah satu metode statistika yang dapat digunakan untuk mengetahui performansi sebuah pompa adalah dengan menggunakan pendekatan regresi polynomial. Bentuk kurva yang didapatkan dari sebuah regresi polynomial dinilai sesuai dengan bentuk kurva kerja pada suatu motor-pompa pada umumnya. Karena suatu kurva motor pompa mempunyai kurva perbandingan yang non linier terhadap setiap perubahannya.

\section{Regresi polynomial}

Regresi polinomial ialah regresi dengan sebuah variabel bebas sebagai faktor dengan pangkat terurut. Bentuk-bentuk fungsinya adalah sebagai berikut.

1. $Y=a+b X+c X^{2}$ (fungsi kuadratik).

2. $Y=a+b X+c X^{2}+b X^{3}$ (fungsi kubik)

3. $Y=a+b X+c X^{2}+d X^{3}+e X^{4}$ (fungsi kuartik),

4. $Y=a+b X+c X^{2}+d X^{3}+e X^{4}+f X^{5}$ (fungsi kuinik), dan seterusnya.

Atau untuk polinomial derajad tiga atau lebih persamaan kurvanya dapat ditulis sebagai berikut :

$$
y=a_{0}+a_{1} X+\ldots+a_{m} X^{m}
$$

dengan $\mathrm{m}$ adalah derajad polinomialnya dan $\mathrm{a}_{\mathrm{i}}$ untuk $i=0 \mathrm{~s} / \mathrm{d} m$ adalah konstanta yang dapat dihitung.

\section{HASIL PENELITIAN}

Telah disebutkan sebelumnya bahwa performansi masing-masing motor-pompa dapat diketahui dengan menggunakan pendekatan regresi polynomial. Penelitian ini akan mengaplikasikan pendekatan regresi polynomial untuk mengetahui perubahan laju aliran air pada masing-masing motor-pompa pada stasiun pompa Jakarta IPA 1 khususnya motor-pompa yang telah dipasang MV-VSD. Seperti telah diketahui bahwa MV-VSD merupakan suatu peralatan yang dibutuhkan untuk mengatur kecepatan putaran motor dengan cara mengatur input frekuensi pada motor tersebut. Pada penelitian ini akan diaplikasikan penggunaan pendekatan regresi polynomial dengan menggunakan variable pengaruh perubahan kecepatan putaran motor (rpm) dengan perubahan laju aliran air pada pompa distribusi stasiun pompa Jakarta IPA 1.

Pada saat melakukan pengujian motor-pompa nomor 2, data perubahan kecepatan putaran motor ( RPM ) dan kecepatan laju aliran air ( flow / detik ) hanya dapat terukur pada saat frekuensi pada MVVSD di-set pada frekuensi $25 \mathrm{~Hz}$ sampai dengan $38 \mathrm{~Hz}$ ( Tabel 1).

Dengan menggunakan data hasil pengukuran yaitu pengaruh perubahan kecepatan motor dengan laju kecepatan aliran air pada saat frekuensi MV-VSD berada di angka $25 \mathrm{~Hz}-38 \mathrm{~Hz}$, maka didapatkan kurva polynomial dari motor-pompa nomor 2 adalah sebagai berikut: 


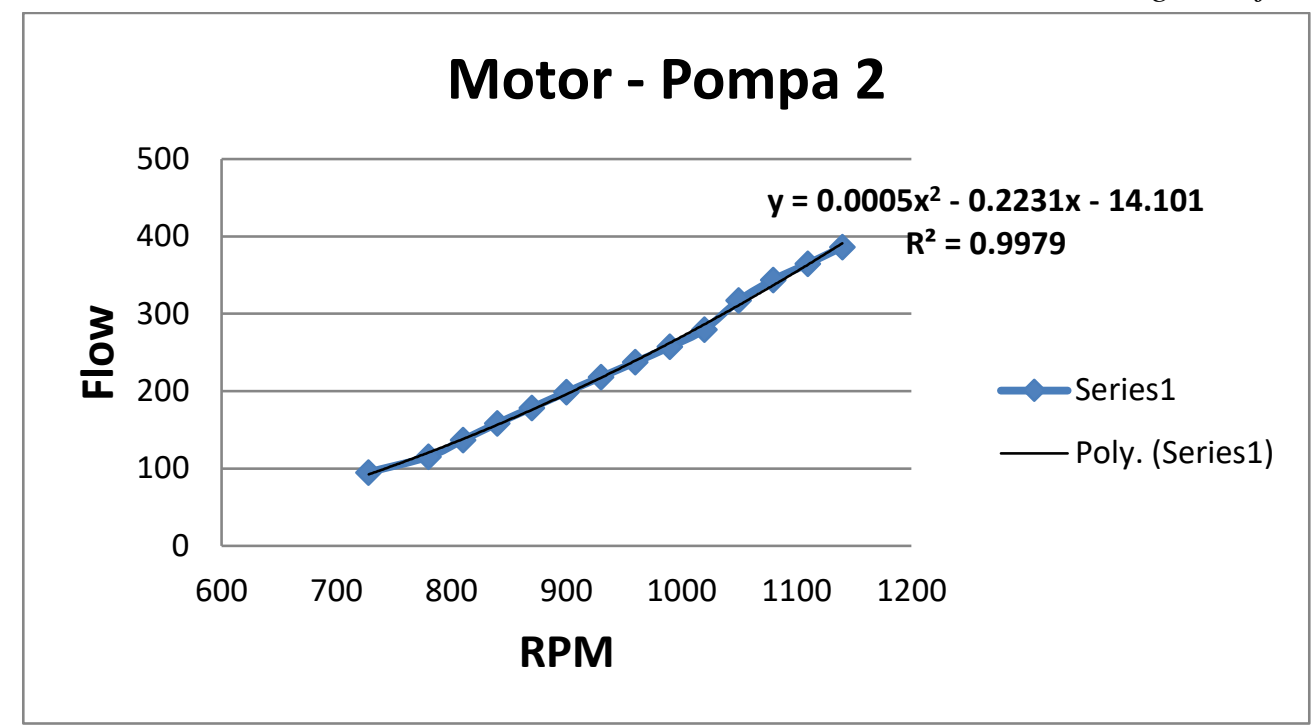

Gambar 2 Kurva Polynomial Motor-Pompa nomor 2

Hasil pengolahan data menunjukkan bahwa nilai $\mathrm{R}^{2}$ sebesar 0,9979 , hal ini berarti hubungan antara Variabel Independen dengan Variabel Dependen dalam penelitian tersebut dapat dikatakan mempunyai hubungan yang kuat atau erat karena mendekati $100 \%$.

Dari koefisien-koefisien terukur yang didapatkan dari pengujian pada frekuensi $25 \mathrm{~Hz}$ sampai dengan $38 \mathrm{~Hz}$, telah didapatkan pengaruh rumus koefisien Polynomial perubahan kecepatan terhadap perubahan laju aliran air pada motor-pompa nomor 2, yaitu sebagai berikut :

$$
Q=0.0005 N^{2}-0.2231 N-14.101
$$

Dimana :

$\mathrm{Q}=$ Laju aliran air $(1 / \mathrm{s})$

$\mathrm{N}=$ Kecepatan putaran motor $(\mathrm{rpm})$

Kecepatan putaran motor pada saat frekuensi MV-VSD diset pada frekuensi $39 \mathrm{~Hz}$ adalah $1169 \mathrm{rpm}$. Dengan menggunakan rumus (10) di atas, maka kita dapat mengetahui kecepatan laju aliran air motorpompa nomor 2 pada saat frekuensi pada MV-VSD diset pada frekuensi $39 \mathrm{~Hz}$ :

$\mathrm{Q}_{39 \mathrm{~Hz}}=0.0005(1169)^{2}-0.2231(1169)-14.101$

$\mathbf{Q}_{39 \mathrm{~Hz}}=\mathbf{4 0 8 . 4 1 / \mathrm { s }}$

Maka, dengan menggunakan cara yang sama seperti cara di atas. Dapat diketahui performansi motorpompa nomor 2 di setiap kenaikan frekuensinya dimulai dari frekuensi $25 \mathrm{~Hz}$ sampai dengan frekuensi $50 \mathrm{~Hz}$ seperti pada tabel 1 berikut ini : 
-Tabel 1 Performansi motor-pompa nomor 2

\begin{tabular}{|c|c|c|c|c|c|c|c|c|c|}
\hline $\begin{array}{c}\text { Freq } \\
\text { P2 }\end{array}$ & \multirow{2}{*}{$\begin{array}{l}\text { N P2 } \\
\text { (rpm) }\end{array}$} & \multirow{2}{*}{$\begin{array}{c}\text { Q P2 } \\
(\mathbf{l} / \mathbf{s}) \\
\end{array}$} & \multirow{2}{*}{$\begin{array}{c}\text { TDH } \\
\text { (meter) }\end{array}$} & \multirow{2}{*}{$\begin{array}{c}\text { WP } \\
(\mathrm{kW})\end{array}$} & \multirow{2}{*}{$\begin{array}{c}P \\
\text { motor } \\
(\mathbf{k W}) \\
\end{array}$} & \multirow{2}{*}{$\begin{array}{c}\begin{array}{r}\text { r } \\
\text { rotor }\end{array} \\
(\mathbf{k W}) \\
\end{array}$} & \multirow{2}{*}{$\frac{\text { P Shaft }}{(\mathrm{kW})}$} & \multicolumn{2}{|c|}{ Efisiensi } \\
\hline $\mathbf{H z}$ & & & & & & & & Pump & Sistem \\
\hline 0.00 & 0.00 & 0.00 & 0.00 & 0.00 & 0.00 & 0.00 & 0.00 & 0.00 & 0.00 \\
\hline 25 & 728 & 95.2 & 9.56 & 8.93 & 49.77 & 46.79 & 42.53 & $21 \%$ & $18 \%$ \\
\hline 26 & 780 & 115.3 & 10.08 & 11.40 & 56.83 & 53.42 & 48.57 & $23 \%$ & $20 \%$ \\
\hline 27 & 810 & 136.9 & 10.57 & 14.20 & 62.62 & 58.87 & 53.51 & $27 \%$ & $23 \%$ \\
\hline 28 & 840 & 158.5 & 11.07 & 17.21 & 67.87 & 63.80 & 58.00 & $30 \%$ & $25 \%$ \\
\hline 29 & 870 & 178.6 & 11.56 & 20.25 & 67.51 & 63.46 & 57.69 & $35 \%$ & $30 \%$ \\
\hline 30 & 900 & 198.7 & 11.56 & 22.53 & 70.23 & 66.01 & 60.01 & $38 \%$ & $32 \%$ \\
\hline 31 & 930 & 218.2 & 12.06 & 25.81 & 76.92 & 72.31 & 65.73 & $39 \%$ & $34 \%$ \\
\hline 32 & 960 & 237.5 & 12.55 & 29.24 & 84.16 & 79.11 & 71.92 & $41 \%$ & $35 \%$ \\
\hline 33 & 990 & 257.4 & 13.05 & 32.95 & 91.76 & 86.26 & 78.42 & $42 \%$ & $36 \%$ \\
\hline 34 & 1020 & 279.6 & 13.55 & 37.17 & 99.55 & 93.57 & 85.07 & $44 \%$ & $37 \%$ \\
\hline 35 & 1050 & 317.2 & 13.55 & 42.16 & 107.51 & 101.06 & 91.87 & $46 \%$ & $39 \%$ \\
\hline 36 & 1080 & 343.9 & 12.54 & 42.31 & 116.74 & 109.74 & 99.76 & $42 \%$ & $36 \%$ \\
\hline 37 & 1110 & 364.7 & 13.05 & 46.69 & 125.79 & 118.24 & 107.49 & $43 \%$ & $37 \%$ \\
\hline 38 & 1140 & 386.3 & 11.1 & 42.06 & 135.02 & 126.92 & 115.38 & $36 \%$ & $31 \%$ \\
\hline 39 & 1169 & 408.38 & 9.89 & 39.62 & 143.89 & 135.26 & 122.96 & $32 \%$ & $28 \%$ \\
\hline 40 & 1199 & 437.2 & 9.83 & 42.16 & 152.40 & 143.25 & 130.23 & $32 \%$ & $28 \%$ \\
\hline 41 & 1229 & 466.93 & 10.27 & 47.04 & 162.35 & 152.61 & 138.74 & $34 \%$ & $29 \%$ \\
\hline 42 & 1259 & 497.56 & 10.24 & 49.98 & 174.30 & 163.84 & 148.94 & $34 \%$ & $29 \%$ \\
\hline 43 & 1290 & 530.15 & 10.77 & 56.01 & 185.70 & 174.56 & 158.69 & $35 \%$ & $30 \%$ \\
\hline 44 & 1340 & 584.75 & 10.24 & 58.74 & 198.19 & 186.30 & 169.36 & $35 \%$ & $30 \%$ \\
\hline 45 & 1349 & 594.84 & 10.71 & 62.50 & 212.12 & 199.40 & 181.27 & $34 \%$ & $29 \%$ \\
\hline 46 & 1379 & 629.06 & 11.17 & 68.93 & 223.26 & 209.86 & 190.78 & $36 \%$ & $31 \%$ \\
\hline 47 & 1408 & 663.01 & 11.17 & 72.65 & 238.37 & 224.07 & 203.70 & $36 \%$ & $30 \%$ \\
\hline 48 & 1438 & 699 & 11.17 & 76.60 & 251.22 & 236.15 & 214.68 & $36 \%$ & $30 \%$ \\
\hline 49 & 1468 & 735.9 & 11.17 & 80.64 & 264.79 & 248.91 & 226.28 & $36 \%$ & $30 \%$ \\
\hline 50 & 1496 & 771.15 & 11.17 & 84.50 & 278.01 & 261.33 & 237.57 & $36 \%$ & $30 \%$ \\
\hline
\end{tabular}

Pada saat melakukan pengujian motor-pompa nomor 3, data perubahan kecepatan putaran motor ( RPM ) dan kecepatan laju aliran air ( flow / detik ) hanya dapat terukur pada saat frekuensi pada MVVSD di-set pada frekuensi $41 \mathrm{~Hz}$ sampai dengan $50 \mathrm{~Hz}$ ( Tabel 2).

Dengan menggunakan data hasil pengukuran yaitu pengaruh perubahan kecepatan motor dengan laju kecepatan aliran air pada saat frekuensi MV-VSD berada di angka $41 \mathrm{~Hz}-50 \mathrm{~Hz}$, maka didapatkan kurva polynomial dari motor-pompa nomor 3 adalah sebagai berikut: 


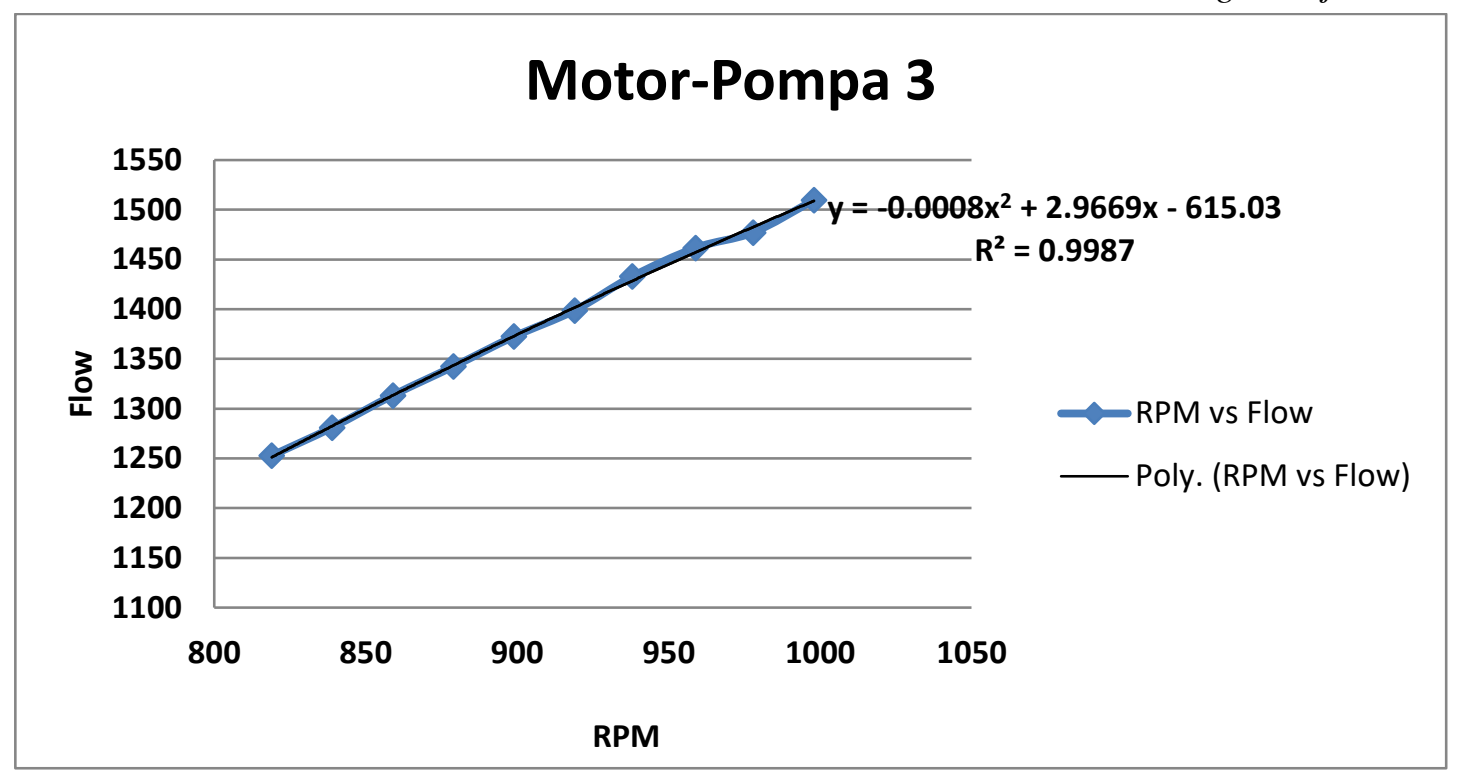

- Gambar 3 Kurva Polynomial Motor-Pompa nomor 3

Dari koefisien-koefisien yang terdapat pada tabel 2, telah didapatkan pengaruh rumus perubahan kecepatan terhadap perubahan laju aliran air pada motor-pompa nomor 3, yaitu sebagai berikut :

$$
Q=-0.0008 N^{2}+0.29669 N-615.03
$$

Dimana :

$\mathrm{Q}=$ Laju aliran air ( 1/s)

$\mathrm{N}=$ Kecepatan putaran motor $(\mathrm{rpm})$

Diketahui dari tabel 2 kecepatan putaran motor pada saat frekuensi MV-VSD diset pada frekuensi 25 $\mathrm{Hz}$ adalah $500 \mathrm{rpm}$.Dengan menggunakan rumus (11) di atas, maka kita dapat mengetahui kecepatan laju aliran air motor-pompa nomor 3 pada saat frekuensi pada MV-VSD diset pada frekuensi $25 \mathrm{~Hz}$ :

$\mathrm{Q}_{25 \mathrm{~Hz}}=-0.0008(500)^{2}+0.29669(500)-615.03$

$\mathbf{Q}_{25 \mathrm{~Hz}}=\mathbf{6 6 8 . 4 2} \mathrm{l} / \mathrm{s}$

Dengan cara dan langkah yang sama, maka kita dapat mengetahui performansi dari motor-pompa nomor 3 pada tabel 2 di bawah ini. 
- Tabel 2 Performansi motor-pompa nomor 3

\begin{tabular}{|c|c|c|c|c|c|c|c|c|c|}
\hline $\begin{array}{c}\text { Freq } \\
\text { P3 }\end{array}$ & N P3 & Q P3 & TDH & WP & $\begin{array}{c}\mathbf{P} \\
\text { motor }\end{array}$ & $\begin{array}{c}\mathbf{P} \\
\text { rotor }\end{array}$ & P Shaft & Efi & iensi \\
\hline $\mathbf{H z}$ & (rpm) & $(\mathbf{l} / \mathbf{s})$ & (meter) & $(\mathbf{k W})$ & $(\mathbf{k W})$ & $(\mathbf{k W})$ & $(\mathbf{k W})$ & Pump & Sistem \\
\hline 0.00 & 0.00 & 0.00 & 0.00 & 0.00 & 0.00 & 0.00 & 0.00 & 0.00 & 0.00 \\
\hline 25 & 500 & 668.42 & 8.79 & 57.64 & 81.45 & 77.37 & 70.34 & $82 \%$ & $71 \%$ \\
\hline 26 & 518 & 707.17 & 9.81 & 68.05 & 86.88 & 82.53 & 75.03 & $91 \%$ & $78 \%$ \\
\hline 27 & 540 & 753.82 & 10.21 & 75.50 & 97.74 & 92.85 & 84.41 & $89 \%$ & $77 \%$ \\
\hline 28 & 560 & 795.55 & 11.2 & 87.41 & 108.60 & 103.17 & 93.79 & $93 \%$ & $80 \%$ \\
\hline 29 & 580 & 836.65 & 11.79 & 96.77 & 119.46 & 113.48 & 103.17 & $94 \%$ & $81 \%$ \\
\hline 30 & 600 & 877.11 & 12.19 & 104.89 & 130.32 & 123.80 & 112.55 & $93 \%$ & $80 \%$ \\
\hline 31 & 619 & 914.95 & 12.89 & 115.70 & 141.18 & 134.12 & 121.92 & $95 \%$ & $82 \%$ \\
\hline 32 & 640 & 956.11 & 8.1 & 75.97 & 162.89 & 154.75 & 140.68 & $54 \%$ & $47 \%$ \\
\hline 33 & 656 & 986.99 & 6.3 & 61.00 & 179.18 & 170.22 & 154.75 & $39 \%$ & $34 \%$ \\
\hline 34 & 680 & 1032.5 & 6.43 & 65.13 & 195.47 & 185.70 & 168.82 & $39 \%$ & $33 \%$ \\
\hline 35 & 700 & 1069.8 & 6.57 & 68.95 & 211.76 & 201.17 & 182.89 & $38 \%$ & $33 \%$ \\
\hline 36 & 719 & 1104.6 & 6.64 & 71.95 & 228.05 & 216.65 & 196.95 & $37 \%$ & $32 \%$ \\
\hline 37 & 740 & 1142.4 & 6.7 & 75.09 & 249.77 & 237.28 & 215.71 & $35 \%$ & $30 \%$ \\
\hline 38 & 759 & 1176 & 6.87 & 79.25 & 260.63 & 247.60 & 225.09 & $35 \%$ & $30 \%$ \\
\hline 39 & 779 & 1210.7 & 4.22 & 50.12 & 282.35 & 268.23 & 243.85 & $21 \%$ & $18 \%$ \\
\hline 40 & 799 & 1244.8 & 5.78 & 70.58 & 304.07 & 288.87 & 262.61 & $27 \%$ & $23 \%$ \\
\hline 41 & 819 & 1252.8 & 6.38 & 78.41 & 325.79 & 309.50 & 281.36 & $28 \%$ & $24 \%$ \\
\hline 42 & 839 & 1281.2 & 7.34 & 92.25 & 347.51 & 330.13 & 300.12 & $31 \%$ & $27 \%$ \\
\hline 43 & 859 & 1313.5 & 7.14 & 92.00 & 374.66 & 355.92 & 323.57 & $28 \%$ & $25 \%$ \\
\hline 44 & 879 & 1342.5 & 7.4 & 97.46 & 396.38 & 376.56 & 342.33 & $28 \%$ & $25 \%$ \\
\hline 45 & 899 & 1372.6 & 8.08 & 108.80 & 423.53 & 402.35 & 365.77 & $30 \%$ & $26 \%$ \\
\hline 46 & 919 & 1398.8 & 8.58 & 117.74 & 456.10 & 433.30 & 393.91 & $30 \%$ & $26 \%$ \\
\hline 47 & 938 & 1433 & 9.17 & 128.91 & 488.68 & 464.25 & 422.05 & $31 \%$ & $26 \%$ \\
\hline 48 & 959 & 1461.8 & 9.86 & 141.40 & 526.69 & 500.36 & 454.87 & $31 \%$ & $27 \%$ \\
\hline 49 & 978 & 1477.3 & 10.06 & 145.79 & 542.98 & 515.83 & 468.94 & $31 \%$ & $27 \%$ \\
\hline 50 & 998 & 1509.7 & 10.65 & 157.73 & 597.28 & 567.42 & 515.83 & $31 \%$ & $26 \%$ \\
\hline
\end{tabular}

Pada saat melakukan pengujian motor-pompa nomor 4, data perubahan kecepatan putaran motor ( RPM ) dan kecepatan laju aliran air ( flow / detik ) hanya dapat terukur pada saat frekuensi pada MVVSD di-set pada frekuensi $34 \mathrm{~Hz}$ sampai dengan $46 \mathrm{~Hz}$ ( Tabel 3).

Dengan menggunakan data hasil pengukuran yaitu pengaruh perubahan kecepatan motor dengan laju kecepatan aliran air pada saat frekuensi MV-VSD berada di angka $34 \mathrm{~Hz}-46 \mathrm{~Hz}$, maka didapatkan kurva polynomial dari motor-pompa nomor 4 adalah sebagai berikut : 


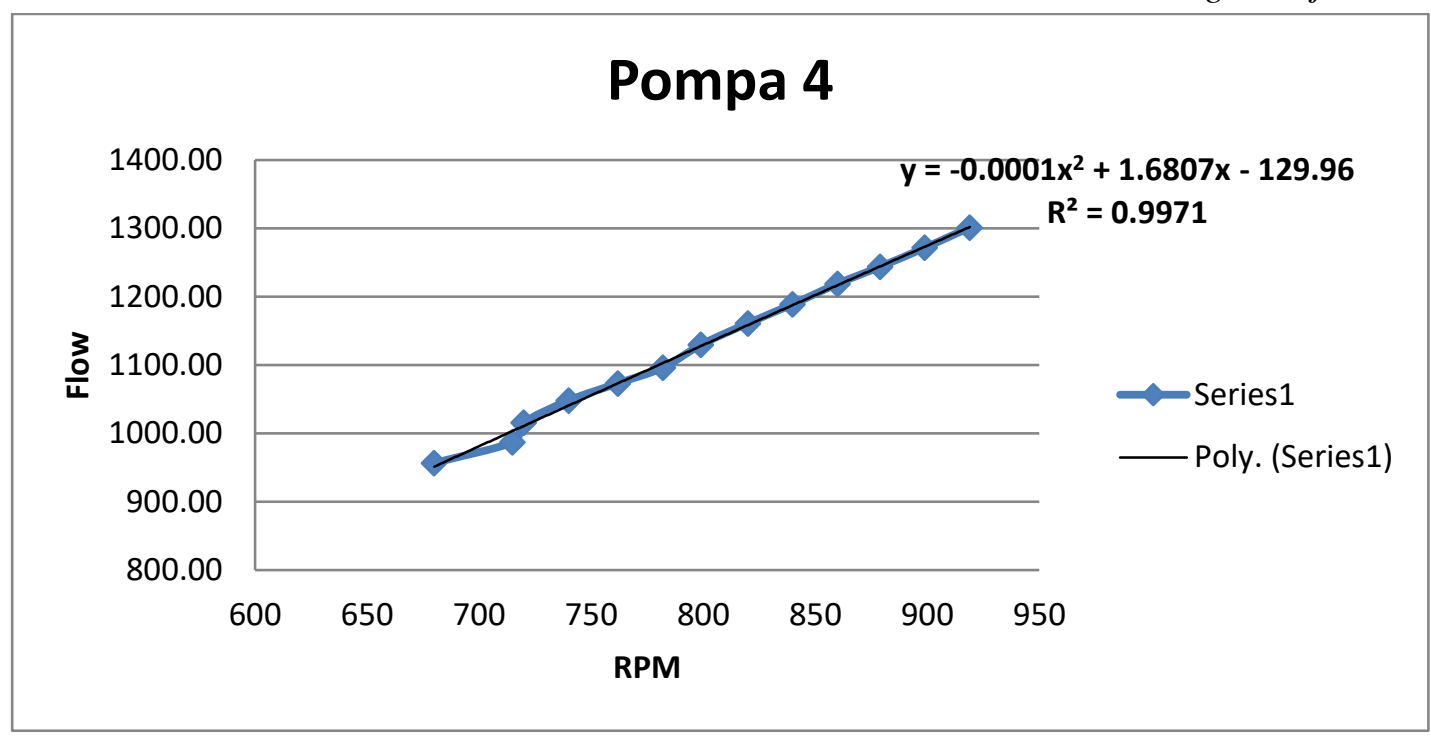

- Gambar 4 Kurva Polynomial Motor-Pompa nomor 4

Hasil pengolahan data menunjukkan bahwa nilai $\mathrm{R}^{2}$ sebesar 0,9971 , hal ini berarti hubungan antara Variabel Independen dengan Variabel Dependen dalam penelitian tersebut dapat dikatakan mempunyai hubungan yang kuat atau erat karena mendekati $100 \%$.

Dari koefisien-koefisien yang terdapat pada tabel 3, telah didapatkan pengaruh rumus perubahan kecepatan terhadap perubahan laju aliran air pada motor-pompa nomor 4, yaitu sebagai berikut :

$$
Q=-0.0001 N^{2}+1.6807 N-129.96
$$

Dimana :

$\mathrm{Q}=$ Laju aliran air $(1 / \mathrm{s})$

$\mathrm{N}=$ Kecepatan putaran motor $(\mathrm{rpm})$

Diketahui dari tabel 3 kecepatan putaran motor pada saat frekuensi MV-VSD diset pada frekuensi 25 $\mathrm{Hz}$ adalah $500 \mathrm{rpm}$. Dengan menggunakan rumus (12) di atas, maka kita dapat mengetahui kecepatan laju aliran air motor-pompa nomor 4 pada saat frekuensi pada MV-VSD diset pada frekuensi $25 \mathrm{~Hz}$ :

$\mathrm{Q}_{25 \mathrm{~Hz}}=-0.0001(500)^{2}+1.6807(500)-129.96$

$\mathrm{Q}_{25 \mathrm{~Hz}}=685.39 \mathrm{l} / \mathrm{s}$

Dengan cara dan langkah yang sama, maka kita dapat mengetahui performansi dari motor-pompa nomor 4 pada tabel 3 di bawah ini. 
- Tabel 3 Performansi motor-pompa nomor 4

\begin{tabular}{|c|c|c|c|c|c|c|c|c|c|}
\hline $\begin{array}{c}\text { Freq } \\
\text { P4 } \\
\end{array}$ & N P4 & Q P4 & TDH & WP & $\begin{array}{c}\mathbf{P} \\
\text { motor }\end{array}$ & $\begin{array}{c}\mathbf{P} \\
\text { rotor }\end{array}$ & P Shaft & Efi: & ensi \\
\hline $\mathrm{Hz}$ & $(\mathbf{r p m})$ & $(\mathbf{l} / \mathbf{s})$ & (meter) & $(\mathbf{k W})$ & $(\mathbf{k W})$ & $(\mathbf{k W})$ & $(\mathrm{kW})$ & Pump & Sistem \\
\hline 0.00 & 0.00 & 0.00 & 0.00 & 0.00 & 0.00 & 0.00 & 0.00 & $0 \%$ & $0 \%$ \\
\hline 20.00 & 400.00 & 526.32 & 5.26 & 27.16 & 49.03 & 46.58 & 42.35 & $64 \%$ & $55 \%$ \\
\hline 25.00 & 500.00 & 685.39 & 8.43 & 56.68 & 66.95 & 63.60 & 57.82 & $98 \%$ & $85 \%$ \\
\hline 26.00 & 520.00 & 716.96 & 8.92 & 62.74 & 74.17 & 70.46 & 64.06 & $98 \%$ & $85 \%$ \\
\hline 27.00 & 539.00 & 746.89 & 8.81 & 64.55 & 81.45 & 77.37 & 70.34 & $92 \%$ & $79 \%$ \\
\hline 28.00 & 560.00 & 779.87 & 10.30 & 78.80 & 92.31 & 87.69 & 79.72 & $99 \%$ & $85 \%$ \\
\hline 29.00 & 581.00 & 812.77 & 10.89 & 86.83 & 101.32 & 96.25 & 87.50 & $99 \%$ & $86 \%$ \\
\hline 30.00 & 600.00 & 842.46 & 10.68 & 88.27 & 110.39 & 104.87 & 95.34 & $93 \%$ & $80 \%$ \\
\hline 31.00 & 617.00 & 868.96 & 4.67 & 39.81 & 123.04 & 116.89 & 106.26 & $37 \%$ & $32 \%$ \\
\hline 32.00 & 640.00 & 904.73 & 5.61 & 49.79 & 144.76 & 137.52 & 125.02 & $40 \%$ & $34 \%$ \\
\hline 33.00 & 660.00 & 935.74 & 5.59 & 51.31 & 157.46 & 149.59 & 135.99 & $38 \%$ & $33 \%$ \\
\hline 34.00 & 680.00 & 956.71 & 3.07 & 28.81 & 170.12 & 161.61 & 146.92 & $20 \%$ & $17 \%$ \\
\hline 35.00 & 715.00 & 987.31 & 2.99 & 28.96 & 180.98 & 171.93 & 156.30 & $19 \%$ & $16 \%$ \\
\hline 36.00 & 720.00 & 1015.91 & 3.47 & 34.58 & 191.67 & 182.09 & 165.54 & $21 \%$ & $18 \%$ \\
\hline 37.00 & 740.00 & 1048.21 & 3.45 & 35.48 & 207.96 & 197.56 & 179.60 & $20 \%$ & $17 \%$ \\
\hline 38.00 & 762.00 & 1073.41 & 3.94 & 41.49 & 222.62 & 211.49 & 192.26 & $22 \%$ & $19 \%$ \\
\hline 39.00 & 782.00 & 1096.21 & 3.93 & 42.26 & 238.91 & 226.97 & 206.33 & $20 \%$ & $18 \%$ \\
\hline 40.00 & 799.00 & 1129.71 & 4.42 & 48.98 & 258.79 & 245.85 & 223.50 & $22 \%$ & $19 \%$ \\
\hline 41.00 & 820.00 & 1161.21 & 4.41 & 50.24 & 276.92 & 263.07 & 239.16 & $21 \%$ & $18 \%$ \\
\hline 42.00 & 840.00 & 1189.21 & 5.40 & 63.00 & 293.21 & 278.55 & 253.23 & $25 \%$ & $21 \%$ \\
\hline 43.00 & 860.00 & 1219.01 & 5.69 & 68.04 & 316.56 & 300.73 & 273.39 & $25 \%$ & $21 \%$ \\
\hline 44.00 & 879.00 & 1243.91 & 5.68 & 69.31 & 285.61 & 271.33 & 246.66 & $28 \%$ & $24 \%$ \\
\hline 45.00 & 899.00 & 1271.81 & 6.87 & 85.71 & 361.63 & 343.54 & 312.31 & $27 \%$ & $24 \%$ \\
\hline 46.00 & 919.00 & 1301.51 & 6.35 & 81.09 & 381.72 & 362.63 & 329.66 & $25 \%$ & $21 \%$ \\
\hline 47.00 & 934.00 & 1352.58 & 5.51 & 73.08 & 410.49 & 389.97 & 354.52 & $21 \%$ & $18 \%$ \\
\hline 48.00 & 958.00 & 1388.37 & 4.95 & 67.42 & 445.25 & 422.98 & 384.53 & $18 \%$ & $15 \%$ \\
\hline 49.00 & 979.00 & 1419.60 & 4.47 & 62.25 & 483.25 & 459.09 & 417.36 & $15 \%$ & $13 \%$ \\
\hline 50.00 & 998.00 & 1447.78 & 4.06 & 57.73 & 504.97 & 479.72 & 436.11 & $13 \%$ & $11 \%$ \\
\hline
\end{tabular}

\section{KESIMPULAN}

Dengan menggunakan data kecepatan putaran motor dan data laju aliran air yang didapat pada saat pengujian dilakukan pada pompa nomor 2,3 dan 4 akan didapatkan karakteristik grafik polynomial seperti yang tertera pada gambar 2, 3, dan 4 .

Karakteristik grafik polynomial akan menghasilkan suatu fungsi kuadrat yang dapat dipakai untuk mencari variabel laju kecepatan air yang tidak terukur pada saat melakukan pengujian. Dari hasil perhitungan koefisien polynomial pompa nomor 2 didapatkan rumus untuk mencari nilai laju kecepatan air adalah $\mathrm{Q}=0.0005 \mathrm{~N}^{2}-0.2231 \mathrm{~N}-14.101$ dengan nilai $\mathrm{R}^{2}$ sebesar $99,79 \%$, pompa nomor 3 adalah $\mathrm{Q}=-0.0008 \mathrm{~N}^{2}+0.29669 \mathrm{~N}-615.03$ dengan nilai $\mathrm{R}^{2}$ sebesar $99,87 \%$ dan pompa nomor 4 adalah $\mathrm{Q}$ $=-0.0001 \mathrm{~N}^{2}+1.6807 \mathrm{~N}-129.96$ dengan nilai $\mathrm{R}^{2}$ sebesar $99,71 \%$.

Dari hasil perhitungan didapatkan bahwa kecapatan putaran motor selain berpengaruh pada laju kecepatan air, juga sangat berpengaruh pada daya listrik terpakai dari motor tersebut. Didapatkan bahwa 
pada motor pompa nomor 2, pada saat motor berputar pada kecepatan 728 RPM akan menghasilkan laju kecepatan air sebesar 95,2 liter / detik dan daya listrik terpakai untuk motor tersebut adalah sebesar 49,77 kW. Pada saat motor pompa nomor 2 berputar pada kecepatan 1496 RPM akan menghasilkan laju kecepatan air sebesar 771,15 liter/detik dan daya listrik terpakai untuk motor tersebut adalah sebesar $278,01 \mathrm{~kW}$.

\section{DAFTAR REFERENSI}

[1] Ir. Samboho Sumani, “ Ekonomi Teknik dan Manajemen ", Sekolah Tinggi Teknik Yayasan Pendidikan dan Kesejahteraan PT.PLN ( PERSERO ), Januari 2005.

[2] N. Dizadji, P. Entezar, A. Shabani, "Energy Savings in Pumps ",World Academy of Science, Engineering and Technology, Vol:61, January 29 ${ }^{\text {th }}, 2012$.

[3] Dr. Mariano David Zerquera Izquierdo, Dr. Juan José Sánchez Jiménez, Dr. Alexis Martinez del Sol, "Matlab Software to Determine the Saving in Parallel Pumps Optimal Operation Systems, by Using Variable Speed “, IEEE Energy2030, Atlanta, GA USA, 17-18 November, 2008.

[4] Kiran Deshpande, Rajesh M. Holmukhe, and Yogesh S.Angal, "Determination of Energy Savings in Pumps in Parallel Optimal Operation System at Ravet Pumping Station (at Pune, Maharashtra State, India) by using Matlab Software and Variable Speed Drive", 16th international Conference on Electrical Engineering, Busan Korea, July 11-14, 2010.

[5] Puji Saksono, "Analisis Efisiensi Pompa Centrifugal Pada Instalasi Pengolahan Aair Kampung Damai Balikpapan “, Teknik Mesin, Universitas Balikpapan.

[6] www.energyefficiencyasia.org, " Pedoman Efisiensi Energi untuk Industri “, UNEP, 2006.

[7] Prih Sumardjati, Sofian Yahya, Ali Mashar, " Teknik Pemanfaatan Tenaga Listrik Jilid 3 ",Direktorat Pembinaan Sekolah Menengah Kejuruan, 2008.

[8] Ciaran Walsh, “ Key Managemenet Edisi ketiga “, Erlangga, 2003.

[9] Muhammad Nahar, " Pengaturan Level Ketinggian Air Berbasis Inverter Drive LG-SV008iC5 “, Universitas Indonesia, Desember, 2010.

[10] Ir. Djoko Luknanto M.Sc.,Ph.D, “ Regresi kuadrat terkecil untuk kalibrasi bangunan ukur debit”, Oktober,1992.

[11] Sunyoto, “ Teknik Mesin Industri Jilid 1 “,Direktorat Pembinaan Sekolah Menengah Kejuruan, 2008.

[12] Darmansyah, ST.M.Si, Eko Rigyatno, ST, M. Defri Eldistio, ST , “ Studi efisiensi energi penggunaan MV-VSD pada gedung Instalasi Pengolahan Air I PT. PALYJA “, Januari 2012. 